\title{
ESTUDIO IN VITRO DE LA FERMENTACIÓN RUMINAL DE CARBOHIDRATOS EN CABRA MONTÉS
}

\author{
IN VITRO RUMINAL FERMENTATION OF CARBOHYDRATES BY SPANISH IBEX
}

\author{
Fuente, G. de la ${ }^{1}$, A. Belanche ${ }^{1}$ y M. Fondevila ${ }^{1}$
}

\begin{abstract}
${ }^{1}$ Instituto Universitario de Investigación en Ciencias Ambientales. Departamento de Producción Animal y Ciencia de los Alimentos. Universidad de Zaragoza. Miguel Servet 177. 50013 Zaragoza. España. mfonde@unizar.es
\end{abstract}

\section{Palabras clave adicionales \\ Capra pyrenaica. Producción de gas. Celulosa.} Xilano. Pectina.

\section{RESUMEN}

Se estudió durante $48 \mathrm{~h}$ la cinética de fermentación de pectina, xilano y celulosa a partir de contenido ruminal de cabra montés (machos, MM; hembras, $\mathrm{MH}$ y jóvenes, $\mathrm{MJ}$ ) y de cabra doméstica (CD). No se observaron diferencias $(p>0,05)$ entre inóculos de cabra montés en el volumen de gas producido a ningún tiempo de estudio. La producción de gas fue superior $(p<0,05)$ con los inóculos de MM, MH y MJ que con CD, de 6 a $30 \mathrm{~h}$, de 6 a $16 \mathrm{~h}$ y de 24 a $48 \mathrm{~h}$ con pectina, xilano y celulosa. Para los tres sustratos, los ritmos máximos de fermentación $(\mathrm{ml} / \mathrm{g}$ por $\mathrm{h}$ ) se presentaron antes $y$ fueron más altos para los inóculos de cabra montés. La capacidad fermentativa del inóculo ruminal de cabra montés no se vio influida por el tamaño o sexo del animal, pero mostró un patrón más alto, alcanzando máximos más temprano, que las cabras domésticas.

\section{SUMMARY}

The $48 \mathrm{~h}$ fermentation pattern of pectin, xylan and cellulose from rumen contents of males (MM), females (MH) and kids (MJ) of Spanish Ibex (SI) and from domestic goats (CD) was studied. There were no differences $(p>0.05)$ among $S I$ inocula in total gas production at any incubation time. Gas volume was higher $(p<0.05)$ with all SI inocula than with $\mathrm{CD}$, from 6 to $30 \mathrm{~h}$, from 6 to $16 \mathrm{~h}$ and from 24 to $36 \mathrm{~h}$ with pectin, xylan and cellulose. The maximum rates of fermentation $(\mathrm{ml} / \mathrm{g}$ per $\mathrm{h}$ ) were manifested earlier and more abruptly for SI inocula with all substrates. Fermentative activity of rumen

Recibido: 19-10-07. Aceptado: 17-1-08.

\section{ADDITIONAL KEYWORDS \\ Caprapyrenaica. Gas production. Cellulose. Xylan. Pectin.}

inocula from SI was not influenced by size or age of the donor animal, but it showed a higher level, with maximum rates at an earlier stage of incubation, than domestic goats.

\section{INTRODUCCIÓN}

La cabra montés (Capra pyrenaica) es un rumiante silvestre que habita en los sistemas montañosos de España. La mayoría de los estudios sobre la nutrición y alimentación de esta especie se han enfocado hacia su anatomía digestiva y hábitos de alimentación (Mantecón et al., 1993; Martínez, 1994), pero la cinética de fermentación ruminal está poco documentada.

Se pueden asumir ciertas semejanzas entre cabra montés y cabra doméstica $(C$. hircus) debido a su proximidad genética, tamaño y posiblemente hábitos alimenticios. La cabra doméstica se considera selector intermedio, ya que además de ramonear también consume pastos (Hoffman, 1989). La cabra montés podría tener un comportamiento más selector, con preferencia hacia frutos y hojas tiernas (Cuartas y García-González, 1992), especialmente en invierno a causa de la escasez y baja calidad de los pastos. Martínez (1994) indica que la dieta de cabra montés en invierno se basa en un $88 \%$ de vegetación arbustiva, $8 \%$ de 


\section{DE LA FUENTE, BELANCHE Y FONDEVILA}

gramíneas y 4\% de herbáceas no gramíneas.

La cabra montés muestra un marcado dimorfismo sexual, pesando las hembras entre 30 y $40 \mathrm{~kg}$ y alcanzando los machos los $90 \mathrm{~kg}$. Dado que animales más grandes consumen más, y que el menor tamaño y mayores necesidades de los individuos jóvenes pueden promover una selección de alimentos en función de la calidad (Kay et al., 1980), las estrategias alimenticias entre machos, hembras y jóvenes se suponen diferentes, siendo los machos más ramoneadores, los jóvenes más pastadores y estando las hembras en un nivel intermedio (Cuartas et al., 1996). Este diferente comportamiento alimentario redundaría en diferencias en el ambiente ruminal que impliquen un distinto patrón de fermentación.

Este artículo estudia in vitro el patrón de fermentación de tres carbohidratos puros (celulosa, xilano y pectina) empleando como inóculo contenido ruminal de cabra montés, considerando como variables el sexo y la edad. Como referencia, también se incluyó en el estudio contenido ruminal de tres individuos de cabra doméstica.

\section{MATERIAL Y MÉTODOS}

Quince ejemplares de C. pyrenaica hispanica fueron abatidos entre diciembre de 2005 y febrero de 2006 en los términos municipales de Villarluengo y Pitarque (Maestrazgo, Teruel) por cazadores deportivos bajo la supervisión del SEPRONA (Diputación General de Aragón). La zona se encuentra entre 1100 a 1500 m de altitud, a $5^{\circ} \mathrm{C}$ de temperatura media y $128 \mathrm{~mm} / \mathrm{m}^{2} \mathrm{de}$ precipitación media durante los cuatro meses de muestreo. Tras el sacrificio, los animales se distribuyeron en tres grupos en función de su sexo y edad: machos adultos (MM; $\mathrm{n}=4)$, hembras adultas $(\mathrm{MH} ; \mathrm{n}=7)$ y animales jóvenes (MJ, machos y hembras menores de 2 años; n= 4). En todos los casos, las muestras fueron tomadas durante la primera hora post mórtem. Además, tres hembras adultas y sanas de C. hircus (CD) de un rebaño local, alimentadas exclusivamente a pasto, fueron sacrificadas a las 16:00, después del periodo de pastoreo diario. En todos los casos, se mantuvo el mismo protocolo para la toma y el procesado de las muestras.

Tras el sacrificio, el contenido ruminal fue muestreado y filtrado con una doble capa de gasa, y se determinó el $\mathrm{pH}$ del filtrado. Se tomó una muestra $(10 \mathrm{ml}) \mathrm{del}$ filtrado, que se congeló inmediatamente en $\mathrm{N}$ líquido para su transporte a la Universidad de Zaragoza, siendo posteriormente almacenada $\mathrm{a}-80^{\circ} \mathrm{C}$ hasta la determinación de la cinética de fermentación. Otra muestra (5 $\mathrm{ml})$ se recogió $1: 1$ en formaldehído al $18,5 \%$ y se conservó a temperatura ambiente hasta el recuento de bacterias y protozoos totales.

La incubación se realizó en tubos Hungate (16 ml de volumen total), siguiendo el protocolo descrito por Theodorou et al. (1994), con las modificaciones de Mould et al. (2005). Cada inóculo fue valorado en cinco tubos: tres de ellos incluyeron $100 \mathrm{mg}$ de sustrato (celulosa, xilano o pectina) y otros dos tubos sin sustrato, que se consideraron como blancos. Debido al elevado número de tubos, el experimento se distribuyó en dos tandas de incubación. Como estándar, en cada tanda se incluyó una muestra de inóculo procedente de dos ovejas canuladas del Servicio de Experimentación Animal (Universidad de Zaragoza), alimentadas con heno de alfalfa.

El día anterior a la incubación, los sustratos se suspendieron en la solución de incubación según la concentración requerida, en ambiente de $\mathrm{CO}_{2}$, y los tubos se llenaron con $9 \mathrm{ml}$ del medio correspondiente. Para su procesado, los tubos se inocularon con $1 \mathrm{ml}$ de muestra ruminal, se ajustó la presión inicial a 0 , y se mantuvieron en baño de agua a $39^{\circ} \mathrm{C}$ por $48 \mathrm{~h}$. Se determinó la presión interna de los tubos, como índice de la fermentación, a las 2, 4, 6, 8, 10, 12, 16, 24, 30,36 y $48 \mathrm{~h}$ de incubación mediante un manómetro HD8804 con una sonda TP804 


\section{FERMENTACIÓN RUMINAL EN CABRA MONTÉS}

(DELTA OHM, Padova, Italia). Las lecturas de presión se convirtieron a volumen usando una regresión lineal preestablecida en las mismas condiciones $(n=24 ; r=0,994)$. El volumen de gas por cada tiempo de incubación se expresó por unidad de sustrato incubado.

La concentración total de bacterias del filtrado ruminal se determinó por recuento directo en cámara de Thoma de $0,1 \mathrm{~mm}$ de profundidad y $0,0025 \mathrm{~mm}^{2}$ de área con un microscopio de contraste de fases (x 600). La concentración total de protozoos se determinó por recuento óptico (x100) siguiendo el método de Dehority (1984). La concentración de microorganismos fue expresada en base logarítmica $(\log / \mathrm{ml})$.

Los resultados se analizaron estadísticamente por análisis de varianza de una vía con Statistix 8.0 (Analytical Software, 2003), y las medias que mostraron diferencias fueron comparadas entre sí por la mínima diferencia significativa a una $\mathrm{p}<0,05$.

\section{RESULTADOS}

La edad y el peso estimados de los individuos de cabra montés variaron de 5 a 9 años y 40 a $55 \mathrm{~kg}$ para machos, 5 a 14 años y 32 a $40 \mathrm{~kg}$ para hembras, y de 5 a 20 meses y 8 a $18 \mathrm{~kg}$ para jóvenes. No se observaron

Tabla I. $p H$ y concentración total de bacterias y protozoos $\left(\log _{10} / \mathrm{ml}\right)$ de contenido $\mathrm{ru}$ minal de cabra montés (machos, MM; hembras, $M H$; jóvenes, MJ) y cabra doméstica (CD). ( $\mathrm{pH}$ and total bacterial and protozoal concentration of rumen contents from Spanish Ibex (males, MM; females, MH; kids, MJ) and domestic goats $(C D)$ ).

\begin{tabular}{lccccc}
\hline & MM & MH & MJ & CD & D.E. \\
\hline pH & 6,50 & 6,18 & 6,49 & 6,01 & 0,445 \\
Bacterias & 9,158 & 9,025 & 8,927 & 9,085 & 0,1943 \\
Protozoos & 6,053 & 5,889 & 6,134 & 5,701 & 0,2533
\end{tabular}

D.E.: desviación estándar diferencias entre los tipos de animales estudiados en el pH ruminal al sacrificio, ni en la concentración de bacterias ni protozoos ( $p>0,10)$, como muestra la tabla I.

El patrón de fermentación microbiana de la pectina se muestra en la figura 1, tanto en valores absolutos $(\mathrm{ml} / \mathrm{g}$; figura 1a) o relativos $(\mathrm{ml} / \mathrm{g}$ por $\mathrm{h}$; figura $1 \mathbf{b})$. No se observaron diferencias $(p>0,10)$ entre $\mathrm{MM}, \mathrm{MH}$ y
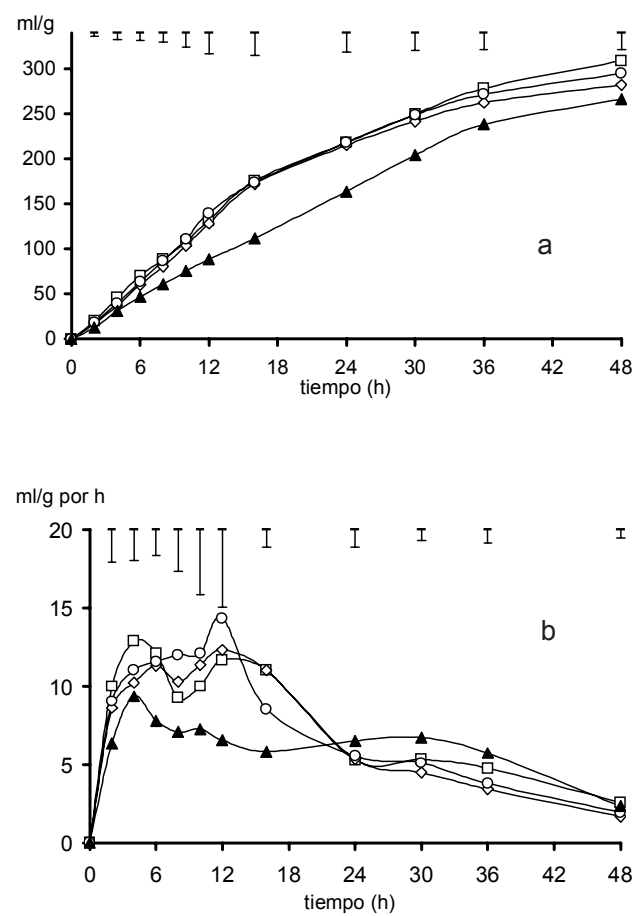

Figura 1. Cinética de producción de gas ( $\mathrm{ml} /$ $g$ sustrato; a) y ritmo de producción de gas ( $\mathrm{ml} / \mathrm{g}$ sustrato por hora; b) a partir de la incubación in vitro de pectina con contenido ruminal de cabra montés ( $\diamond$ machos, MM; $\bigcirc$ hembras, $\mathrm{MH}$; $\square$ jóvenes, MJ) y cabra doméstica $(\mathbf{\Delta C D )}$. Las barras superiores muestran la desviación estándar residual. (Pattern of gas production ( $\mathrm{ml} / \mathrm{g}$ substrate; a) and rate of gas production $(\mathrm{ml} / \mathrm{g}$ substrate per $\mathrm{h} ; \mathrm{b})$ from in vitro incubation of pectin with rumen contents of Spanish Ibex ( $\diamond$ males, MM; $\bigcirc$ females, $\mathrm{MH} ; \square$ kids, MJ) and domestic goat ( $\boldsymbol{\Delta} C D)$. Upper bars show residual standard deviation). 


\section{DE LA FUENTE, BELANCHE Y FONDEVILA}

MJ en la producción total de gas en ningún tiempo de incubación. Por contra, de 6 a 30 $\mathrm{h}$ el volumen de gas fue mayor $(\mathrm{p}<0,05)$ en los tres tipos de cabra montés que en las muestras de CD, y con $\mathrm{MH}$ y MJ se mantuvo por encima de CD a las 36 y $48 \mathrm{~h}$ de incubación $(p<0,05)$. Los tres tipos de cabra montés mostraron dos máximos en el ritmo de fermentación $(\mathrm{ml} / \mathrm{g}$ por $\mathrm{h})$ de pectina, entre 4 y $6 \mathrm{~h}$ y a las $12 \mathrm{~h}$, mientras que las CD mostraron un máximo menor a las $4 \mathrm{~h}$, pero mantuvieron un ritmo de fermentación más elevado a partir de las $24 \mathrm{~h}$.

Del mismo modo, la producción de gas a partir de xilano (figura 2a) fue superior con los inóculos de los tres tipos de cabra montés que con el de CD de $6 \mathrm{a} 16 \mathrm{~h}(\mathrm{p}<0,05)$, pero a las $4 \mathrm{~h}$ y entre 24 y $30 \mathrm{~h}$ las diferencias entre MM y CD no resultaron significativas. Tanto MM como MH y MJ mostraron un máximo de producción de gas $(\mathrm{ml} / \mathrm{g}$ por $\mathrm{h})$ entre 10 y 12 h (figura 2 b), mientras que el ritmo de fermentación en las muestras de CD fue más estable, sin ningún máximo marcado, pero mostrando un ritmo superior de fermentación de 24 h en adelante $(p<0,05)$.

No hubo diferencias entre los inóculos en la fermentación de la celulosa (figura 3a) hasta las $12 \mathrm{~h}$ de incubación $(\mathrm{p}>0,10)$. No obstante, CD mostraron una menor producción de gas que $\mathrm{MJ}$ a las $16 \mathrm{~h}(\mathrm{p}<0,10)$ y que todos los tipos de cabra montés de 24 a 36 $\mathrm{h}(\mathrm{p}<0,05)$. Los ritmos de fermentación de la celulosa (figura 3b) fueron superiores en cabra montés que en CD desde las 24 a las $48 \mathrm{~h}(\mathrm{p}<0,05)$, siento también superiores en MJ que en $\mathrm{MH}$ a las $36 \mathrm{~h}(\mathrm{p}<0,05)$.

\section{DISCUSIÓN}

Este trabajo pretendía comprobar si las diferencias en tamaño, frecuencia de alimentación y ritmo de tránsito, entre ejemplares de machos, hembras y jóvenes de cabra montés podían afectar a la fermentación ruminal, y comparar estos animales con la cabra doméstica. Aunque la importancia del momento de muestreo del contenido
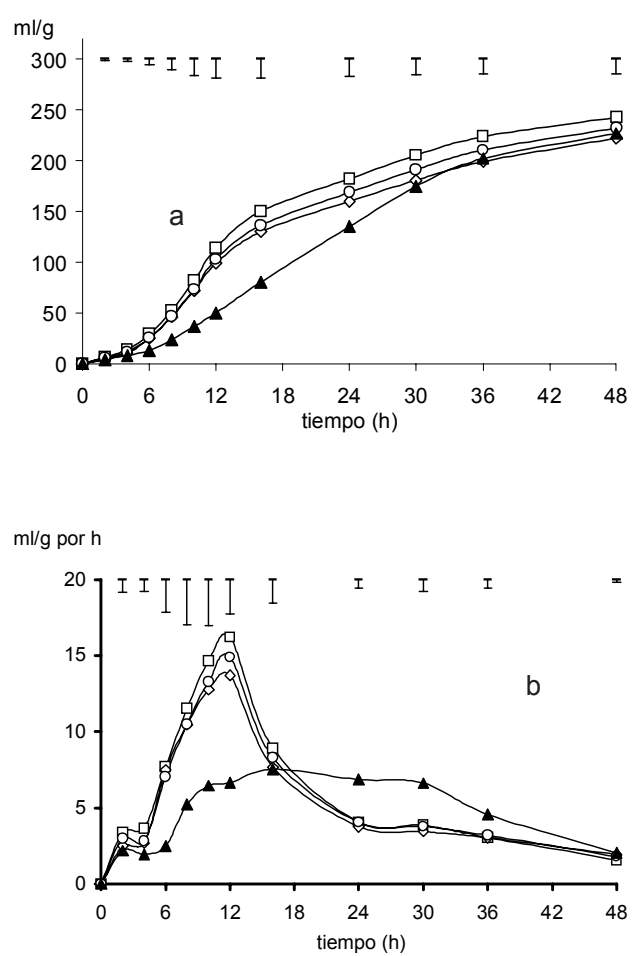

Figura 2. Cinética de producción de gas ( $\mathrm{ml}$ ) $g$ sustrato; a) y ritmo de producción de gas ( $\mathrm{ml} / \mathrm{g}$ sustrato por hora; b) a partir de la incubación in vitro de xilano con contenido ruminal de cabra montés ( $\diamond$ machos, $M M$; $\bigcirc$ hembras, $M H$; $\square$ jóvenes, MJ) y cabra doméstica $(\mathbf{\Delta C D )}$. Las barras superiores muestran la desviación estándar residual. (pattern of gas production ( $\mathrm{ml} / \mathrm{g}$ substrate; a) and rate of gas production ( $\mathrm{ml} / \mathrm{g}$ substrate per $\mathrm{h} ; \mathrm{b})$ from in vitro incubation of xylan with rumen contents of Spanish Ibex ( $\diamond$ males, MM; $O$ females, $\mathrm{MH} ; \square$ kids, MJ) and domestic goat ( $\boldsymbol{\Delta} C D)$. Upper bars show residual standard deviation).

ruminal respecto a la ingestión es evidente, las escasas diferencias en variabilidad intragrupos de los animales (incluyendo las cabras domésticas) en los tres sustratos analizados, permite asumir que su efecto no fue determinante sobre la comparación.

Martínez et al. (1985) y Cuartas et al. (1996) sostienen que el comportamiento ali- 


\section{FERMENTACIÓN RUMINAL EN CABRA MONTÉS}
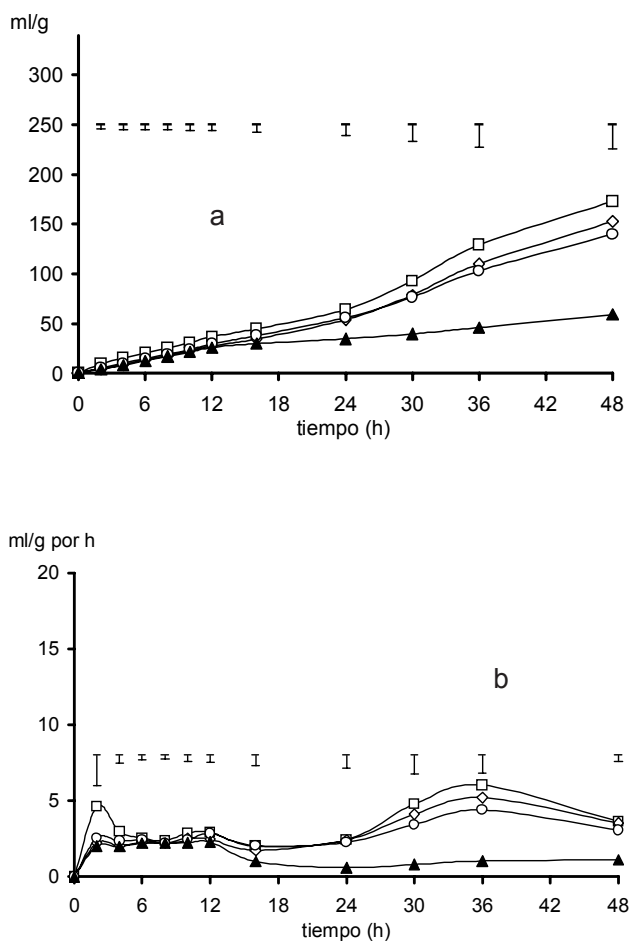

Figura 3. Cinética de producción de gas (ml/ $g$ sustrato; a) y ritmo de producción de gas (ml/g sustrato por hora; b) a partir de la incubación in vitro de celulosa con contenido ruminal de cabra montés ( $\diamond$ machos, MM; O hembras, $M H$; $\square$ jóvenes, $M J)$ y cabra doméstica $(\boldsymbol{\Lambda} C D)$. Las barras superiores muestran la desviación estándar residual. (Pattern of gas production ( $\mathrm{ml} / \mathrm{g}$ substrate; a) and rate of gas production ( $\mathrm{ml} / \mathrm{g}$ substrate per $\mathrm{h}$; b) from in vitro incubation of cellulose with rumen contents of Spanish Ibex ( $\diamond$ males, MM; $O$ females, $\mathrm{MH}$; $\square$ kids, MJ) and domestic goat ( CD). Upper bars show residual standard deviation).

menticio, en términos de selección, es bastante diferente entre los machos, que basan su alimentación en la disponibilidad de nutrientes, y las hembras y en mayor medida las crías, que debido a sus mayores necesidades y menor tamaño seleccionan el alimento en función de su calidad. En la Sierra de Cazorla, de 800 a $1200 \mathrm{~m}$ de altitud,
Martínez (1992) observó que, durante el invierno, la contribución de la vegetación leñosa, representada por diferentes especies, en la dieta total de machos, hembras y crías de cabra montés fue de 80,73 y $79 \%$, respectivamente. Pectina y xilano, como carbohidratos representativos en hojas de arbustos, y celulosa como componente principal de pastos herbáceos, podrían ser fermentados de forma diferente según la población microbiana ruminal adaptada a cada tipo de dieta. Sin embargo, los resultados obtenidos no revelan diferencias aparentes entre los diferentes grupos de cabra montés (machos, hembras y jóvenes) en la cinética de fermentación, tanto en cuanto al volumen de gas producido como a su ritmo de producción, sugiriendo que otros factores, como ritmo de tránsito, podrían estar implicados en diferencias potenciales de fermentación ruminal. Únicamente se manifestó una tendencia a una mayor capacidad fermentativa de xilano y celulosa por el contenido ruminal de los jóvenes comparado con machos y hembras, respectivamente, en la última fase del período de incubación. No obstante, el bajo número de animales estudiados por grupo, en una sola época del año, y la falta de otras referencias en este campo no permiten extraer una conclusión firme.

El contenido ruminal de la cabra montés mostró una mayor capacidad fermentativa que el de la cabra doméstica. Además, el patrón de fermentación fue considerablemente diferente, y los picos de máxima actividad se dieron a diferentes tiempos de incubación. Estas diferencias pueden atribuirse directamente al diferente comportamiento alimenticio de estas especies (Martínez, 1992 y 1994) y también al hecho de que, aun procediendo de la misma zona, las cabras domésticas modifican sus hábitos en función de la manipulación humana. Aunque este hecho pudiera ser más aparente con respecto a la pectina y el xilano, es difícil explicar la menor fermentación de celulosa observada en la cabra doméstica. 


\section{DE LA FUENTE, BELANCHE Y FONDEVILA}

\section{AGRADECIMIENTOS}

Los autores agradecen al Servicio de

\section{BIBLIOGRAFÍA}

Analytical Software. 2003. Statistix 8 for Windows. Analytical Software. Tallahasee, FL.

Cuartas, P. and R. García-González. 1992.

Quercus ilex browse utilization by Caprini in Sierra de Cazorla and Segura (Spain). Vegetatio, 99-100: 317-330.

Cuartas, P., R. García-González, C.L. Alados y J. Escós. 1996. Selección de la dieta y comportamiento alimentario. En: Ecología y comportamiento de la cabra montés, C.L. Alados y J Escós (eds.). Consejo Superior de Investigaciones Científicas. Madrid. p. 151-198.

Dehority, B.A. 1984. Evaluation of subsampling and fixation procedures used for counting rumen protozoa. Appl. Environ. Microb., 48: 182-185. Hoffman, R.R. 1989. Evolutionary steps of ecophysiological adaptation and diversification of ruminants: comparative view of their digestive system. Oecologia, 78: 443-457.

Kay, R.N.B., W.V. Engelhardt and R.G. White. 1980. The digestive physiology of wild ruminants. In: Y. Ruckebusch and P. Thivend (eds.). Digestive physiology and metabolism in ruminants. $p$. 743-761. MTP Press. Lancaster. England.

Mantecón, A.R., P. Lavin, P. Frutos, S. Lavin y I. Marco. 1993. Diferenciación del aparato digestivo de los rumiantes: comparación entre oveja
Protección de la Naturaleza (Diputación General de Aragón) su ayuda en la toma de muestras.

(Ovis aries), rebeco (Rupicapra pyrenaica) y cabra montés (Capra pyrenaica). Arch. Zootec., 42: $445-450$.

Martinez, T. 1992. Estrategia alimentaria de la cabra montes (Capra pyrenaica) y sus relaciones tróficas con los ungulados silvestres y domésticos en Sierra Nevada, Sierra de Gredos y Sierra de Cazorla. Tesis doctoral. Universidad Complutense de Madrid.

Martínez, T. 1994. Dieta estacional de la cabra montés (Capra pyrenaica) en los puertos de Tortosa y Beceite (área mediterránea del Nordeste de España). Ecología, 8: 373-380.

Martínez, T., E. Martínez and P. Fandos. 1985 Composition of the food of the Spanish Wild Goat in Sierras de Cazorla and Segura, Spain. Acta Theriol., 30: 461-494.

Mould, F.L., R. Morgan, K.E. Kliem and E. Krystallidou. 2005. A review and simplification of the in vitro incubation medium. Anim. Feed Sci. Technol., 123-124: 155-172.

Theodorou, M.K., B.A. Williams, M.S. Dhanoa, A.D.B. McAlan and J. France. 1994. A simple gas production method using a pressure transducer to determine the fermentation kinetics of ruminant feeds. Anim. Feed Sci. Technol., 48: 185-197. 